\section{Administration of ECT}

Sir: Ramsay \& Phillips (Psychiatric Bulletin, $1993,17,716-718)$ report on knowledge of ECT and its practical administration by junior psychiatrists in a large London training rotation. Their audit, taken with our work in the West of Scotland (Henderson et al, 1993), confirms that problems with the administration of ECT are not confined to any one area.

There is no doubt that ECT is effective in carefully selected patients, and it behoves mental health services to deliver the treatment in a manner likely to maximise benefit to the patient. Despite College guidelines (Royal College of Psychiatrists, 1989), there seems to have been limited improvement in administration of ECT in the last decade, although there have been structural improvements in services (Pippard, 1992). Poor practice must inevitably expose patients to unnecessary repeat treatments with the hazards of extra general anaesthetics, and potential loss of confidence in ECT as a treatment.

Ramsay \& Phillips make the point that College courses for consultants and senior registrars may result in improvements in administration of ECT. We are less sure that this initiative will be as successful as the College would hope. Informal discussion with senior psychiatrists suggests little lack of knowledge about the administration of ECT. Rather, the problem seems to occur at the level of training of junior doctors and monitoring of administration of ECT. Research into other complex medical skills, such as resuscitation, suggests that skills decay rapidly even in those who have been taught appropriate techniques (Gass \& Curry, 1983), and that evaluation of the effectiveness of training is essential.

We believed that the College should expand its 1989 guidelines to include explicit recommendations on the form of training juniors should receive; how this training should be assessed and how often it should be repeated. A recommendation for yearly audit of ECT cards would also be welcome. Such guidelines could be included as contract standards by purchasers. Mental health services should not be hesitant to scrutinise their performance, and the Royal College of Psychiatrists is best placed to drive forward these improvements.

GASS, D.A. \& CURRY, L. (1983) Physicians and nurses retention of knowiedge and skill after training in cardiopulmonary resuscitation. Canadian Medical Assoctation Journal. 128, 550-551.

HENDERSON, T., ANDERSON, M. \& STARK, C. (1993) Administration of electroconvulsive therapy: training, practice and attitudes. Psychiatric Bulletin, 17, 154-155.

PIPPARD, J. (1992) Audit of electroconvulstve treatment in two National Health Service reglons. British Journal of Psychiatry, 160, 621-637.
ROYAl COLLEge OF PSYCHIATRISTS (1989) The Practical Administration of Electroconvulstue Therapy (ECT). London: Gaskell (Royal College of Psychiatrists).

TOM HENDERSON, The State Hospital, Carstairs Junction, Lanarkshire ML11 8RP; MARILYN ANDERSON, Govan Health Centre, 295 Langlands Road, Glasgow G51; and CAMERON STARK, Department of Public Health, Ross House, Hawkhead Road, Paisley PA2

Sir: Henderson et al can be reassured. The 1994 guidelines will contain recommendations on training which include all the points they make. I would hope that most ECT clinics have moved past the use of ECT cards.

I fully agree with their comments about training and monitoring of administration of ECT. However, it has not been our experience from the ECT courses we have run so far that there is little lack of knowledge among senior psychiatrists. We have been impressed by their openness about their lack of knowledge about up to date ECT techniques and their willingness to learn.

In Scotland the CRAG (Clinical Research and Audit Group) Sub Committee on ECT will shortly produce guidelines on contracts standards for purchases.

The College ECT video, and teaching pack, is now available directly from the College for those who have not attended ECT courses.

C. P. Freeman, Royal Edinburgh Hospital, Edinburgh EH1O 5HF

\section{Philosophy and psychiatry}

Sir: David Foreman states that one of philosophy's strengths is that "it may rationally address areas in psychiatry that seem impervious to a scientific approach, or appear too obvious to question" (Psychiatric Bulletin, 1993, 17. 675-676). We feel it unfortunate that he seems to have a specific, and regrettably narrow, understanding of what philosophy is and what its use for psychiatry may be.

The author's view appears to be shaped by logical empiricism and mentions Carl Hempel's work, lluminating as it is for contemporary efforts of operationalisation in psychiatry. We would argue that future efforts of the special interest group and future research work done "at the interface of philosophy and psychiatry" should also include alternative philosophical concepts. In particular, investigations into diagnostic processes and judgements in psychiatry reveal that it is not mere subsuming under logical classes but rather a situation-tied and project-determined typification which is the most basic and influential step towards diagnosis (Schwartz \& Wiggins, 1986). The use of ideal types informs both an idiographic understanding 
and explanatory theories of generalisable validity of mental phenomena (Frommer \& Frommer, 1990).

A discussion between philosophy and psychiatry may stimulate not only the topic of nosology and categorisation, but also basic epistemological efforts, integrative work at the interface of different language games within psychiatry (Langenbach, 1993), and the link between psychopathological phenomena and everyday life. After all, psychiatric patients are members of the shared social world. Accordingly, philosophy can sharpen concepts of the mental, e.g. by introducing qualitative methods of understanding and researching.

One of the most useful contributions of philosophy to psychiatry, especially in times of prevalling and virtually exclusive methodological interest in operationalisation, is the facilitation of fluid thinking. According to Novalis, a philosopher-poet two centuries ago, philosophy "frees everything and relativises the universe. It neutralises the fixed points, as does the system of Copernicus, and makes the resting a floating".

Frommer, J. \& Frommer, S. (1990) Max Webers Beduetung für den Verstenhensbegriff in der Psychiatrie. Der Nervenarzt, 61, 397-401.

LANGENBACH, M. (1993) Conceptual analyses of psychiatric languages: reductionism and integration of different discourses. Current Opinion in Psychiatry, 6, 698-703.

SCHWARTZ, M.A. \& WIGGINS, O.P. (1986) Logical empiricism and psychiatric classification. Comprehenstue Psychiatry 27, 101-114.

Michael LANGenbach and JÖRg Frommer, Department of Psychosomatic Medicine and Psychotherapy. Hienrich Heine University, Düsseldorf. Germany

Sir: I agree with much of what Drs Langenbach and Frommer say, and am rather surprised that they found my article hostile to their approach to philosophy.

The Philosophy Special Interest Group, while encouraging high standards of philosophical thinking, does not require adherence to any philosophical school. Indeed, many of our members, especially those with psychotherapeutic interests, share Drs Langenbach and Frommer's distaste for logical empiricism. I feel sure the Group would give their views a warm welcome.

I would like to correct one misconception they have: they have implied I believe that Carl Hempel's concepts of classification underpin what psychiatrists actually do. As they so rightly point out, this is not so. However, his work did allow psychiatrists to come to agreements with each other about what would be called schizophrenia, for example. Without such agreement, meaningful debate is of course impossible. Even Martin Buber considered meaning had to be shared before one could relate to the Other
(Buber, 1984). So, Hempel's work is a good example of the utility of philosophy for psychiatry, which was why I chose it. Psychiatrists are practitioners, and rightly require demonstrations of utility as well as truth.

It is, of course, important to debate which philosophical methods are best for addressing which psychiatric problems. I look forward to Drs Frommer and Langenbach developing their arguments in more detail.

BUBER, M. (1984) I and Thou. (Translation) Edinburgh: T \& T Clark.

D. M. FOREMAN, University of Keele, North Staffordshire Hospital Centre, Stoke-on-Trent ST4 7QB

\section{GPs' attitudes towards sectorisation}

Sir: I read with interest Eluned Dorkins article Towards sectorised psychiatric care - what do GPs think?' (Psychiatric Bulletin, 1993, 17, 594596).

Our Community Health Care NHS Trust has a population of 198,000 of which $60 \%$ are registered with GP fund-holders. Having three general psychiatrists, we thought it opportune to 'sectorise' our service for general psychiatry and wrote to all general practitioners with the proposal. The response as a whole was unequivocal and sharp, objecting to not having been consulted, lack of choice of consultant psychiatrist and the difficulties GPs had been experiencing post sectorisation in neighbouring health districts.

Although we felt that sectorisation would have led to a better service, we succumbed to the pressure.

This case illustrates the strength of the market-orientated customer given service and the compromises one has to make within it.

A. K. ChAudhaRY, Scunthorpe Community Care NHS Trust, Scunthorpe General Hospital, Scunthorpe, South Humberside DN15 7BH

\section{The Calman Report on specialist training}

Sir: I would like to respond to the articles by the President and Dr Kisely on the Chief Medical Officer's (Calman) Report on specialist training (Psychiatric Bulletin, 1993, 17, 577-579 and 610-612) on behalf of the CTC.

The CTC welcomes the general recommendations and principles of the Calman Report. We support the President's view that minor changes, building on our current achievements, are needed to meet these recommendations in psychiatry. Policies regarding the structure, content 